\title{
Practice makes perfect: developing public health practice
}

\begin{abstract}
Why do we need a public health practice? What do we mean by practice?

That the relationship between public health practice in an academic setting and public health practice within a health service setting should be close and collaborative is not a recent revelation. ${ }^{1}$ However, still, academic departments can seem remote and out of touch with the day to day realities of work in a health authority; service departments can appear to lack the rigour expected by their academic peers. In a wider context, the local community, by which we mean local government, the business community and the voluntary sector, need to be brought into this collaborative relationship in a way that is mutually supportive and developmental.
\end{abstract}

The concept of stakeholders working in collaboration to produce improvements in the health of the population is not new-it was defined in the World Health Organisation's Health for All strategy and has recently been given greater emphasis through the proposals to create Health Action Zones. ${ }^{23}$

Opportunities for integrated work, across organisational boundaries, may not present themselves; public health practitioners may be less free to become involved in joint work with academic departments or in teaching commitments when demands made on public health activity in a health authority are greater than ever before. The academic sector has not been consistently proactive in forging relationships with the community, and the services and support they could provide remain largely untapped. There are examples of Academic Public Health departments developing close working relationships with local government, community groups or the voluntary sector but this aspect of their work is rarely ascribed a high status in terms of research and is seen as peripheral to the core work of the department. ${ }^{4}$

The challenge is to develop a network that unites research, teaching and service in an academic setting with statutory and non-statutory agencies. A coherent structure would strengthen the public health function-in recognising the wider role of public health and equip practitioners in both service and academic sectors to work more effectively in a multidisciplinary, multisectoral environment.

\section{Academic public health}

Academic public health provides opportunities to develop high quality work in teaching, research, intelligence and analysis across a broad range of themes. In addition, academic departments contribute to a theoretical framework for public health, in the provision of public health training at undergraduate and post-graduate levels and further training, education and continuing professional development programmes for practitioners. There are however limitations in terms of access to training for people from non-health service backgrounds, including members of the community seeking access to public health advice and developing capability.

\section{Research and public health}

Public health research can make a valuable contribution to improvements in the health of the population, especially when it focuses on the interaction of the wider determinants of health from a social as well as a medical perspective. ${ }^{5}$ Through the Research Assessment Exercise academic departments are judged by their research output, which may be to the detriment of work with the health service and in developing relationships with local communities. There is pressure to draw in large scale research grants, which may not enable a more community driven research and practice agenda to thrive and be valued.

The dissemination of results from academic public health research can be difficult if the general applicability of the outcomes is unclear to service public health practitioners working in local communities. There is a need to build on existing opportunities to carry out practice and research in local communities located close to academic institutions. This research should involve local people and forge closer relationships. Community groups should become empowered to identify research topics in which the academic department would act as an advocate. In addition, relationships between the university and the wider community could be strengthened.

A strong base for public health research would enable the academic department to identify new research ideas, build up academic and local expertise and attract new sources of funding. In addition, this would facilitate the development of key skills for public health practitioners in communication, advocacy, proactivism and professionalism.

\section{Training for public health}

There is a need to strengthen aspects of public health training to enable students to apply some of the theoretical learning in a real life situation. This could be achieved if elements of their course were studied in a community setting. Curriculum changes in Master in Public Health and similar programmes may facilitate the provision of this learning experience although there is limited scope in terms of the time available in the curriculum for an optional or specialist study module.

Continuing professional development (CPD) for public health practitioners has been under developed but has the potential to allow experienced practitioners an opportunity to acquire new skills. Linking CPD to an academic department will enable new relationships to be made with service public health departments.

Public health in health authorities-key elements The role of public health in the Health Authority varies from Health Authority to Health Authority-in some the public health team will be regarded as providing a specialist, advisory role whereas in others public health is more involved in the contracting and commissioning process.

The new government has placed renewed emphasis on the role of health authorities as public health organisations with an important role in forging relationships with other agencies and with communities.

\section{Public health practice divisions in the USA}

During the early 1980s there was widespread criticism of the "decoupling" between the practice of public health and its academic base. ${ }^{6}$ This led to the development of Public Health Practice Divisions within 21 of the 27 Schools of Public Health in the USA. The Public Health Practice Division can be described as the realisation of a commitment to a close relationship with the community, providing a focus for liaison between the university and the community and access to a centre of excellence in research, teaching and practice. 
It enables students undertaking public health training and students in other disciplines (most of whom would be regarded as activists in achieving social justice in the community) to undertake a period of intensive work, carrying out projects commissioned by service public health and academic public health departments in the surrounding geographical area, with a marked emphasis on projects requiring the participation of the local community.

Staff in the Public Health Practice Division are drawn from a wide variety of disciplines, including biostatisticians, ethnographers, epidemiologists, community development workers and educationalists.

Examples from the USA include the Department of Public Health at Harvard where Masters of Public Health students are required to undertake a 16 week placement, working in teams of two to four, to undertake a project in the community. The project is expected to reflect a student centred, problem based approach to public health training. This provides students with the opportunity to put the public health skills learnt in the classroom into a community setting, choosing from a very wide range of projects such as a study of the effectiveness of community policing to an assessment of health clinics in local schools or the creation of neighbourhood health promotion programmes. The placement allows students to gain valuable experience in project management, working with communities, becoming familiar with a variety of channels of communication and in practising team work.

Yale University School of Medicine's Department of Epidemiology and Public Health assign students to work in groups of four to six to work on a project selected by the student, drawn from a list covering diverse examples such as an anti-tobacco media campaign targeted towards youth; helping homeless families who are victims of domestic violence; and a comprehensive analysis of the success of an on call programme in primary care.

\section{Developing a public health practice division}

Public Health Practice divisions could be created within existing University Departments of Public Health. The Division would require some full time staff, drawn from a broad multidisciplinary background, and additional "visiting" staff. There may be potential for utilising the Service Increment For Teaching to fund senior lecturer posts in Health Authorities, with a part time commitment to the Public Health Practice Division. Masters students would be encouraged to use the division for elective placements or for the dissertation element of their degree. It may be appropriate for masters students from disciplines other than public health to spend time in the division. Public health practitioners from local health authorities, primary care practitioners and others could be based in the division for short periods as part of their CPD programme. Research projects could range from the short-term project as well as longer term substantive work with a view to publication.

\section{Conclusion}

A Public Health Practice Division would enable academic public health to further develop its potential as a source of expertise for students, practitioners in health purchaser and provider organisations and the wider community, including the business community and voluntary sector.

The interface between academic departments of public health in the universities and service departments of public health in the health authorities would gain strength and greater clarity.

The added value of a Public Health Practice Division for students and others involved in public health training would be in accessing experience and skills in research, community participation and team working.

The Public Health Practice Division would reflect the now widely accepted multi-disciplinary nature of public health. It embodies intersectoral ways of working and promotes pragmatism in learning.

MAGGI MORRIS

JAN HUTCHINSON

Correspondence to: Maggi Morris, 24 Avon Road, Hale, Altrincham, Cheshire WA15 0LB.

1 Committee of Enquiry into the Future Development of the Public Health Function. Public health in England. London: HMSO, 1988. (Cmnd 289.) ("The Acheson report.")

2 World Health Organisation. Global strategy for health for all by the year 2000 Geneva: WHO, 1981

3 Health Action Zones - invitation to bid. London: Department of Health, October 1997. (EL (97) 65.)

4 Hotchkiss J. Croxteth Health Action Area. Community needs, survey and response. (Number 15 in a series of reports from the Liverpool Public Health Observatory.) Liverpool: Liverpool Public Health Observatory, University of Liverpool Department of Public Health, September 1993.

5 Beaglehole R, Bonita R. Public health at the crossroads. Achievements and prospects. Cambridge: Cambridge University Press, 1997:219.

6 pects. Cambridge: Cambridge University Press, 1997:219. The Committee for the Study of the Future of Public Health. Report on
future of public health. Washington DC: National Academy Press, 1988. 